Research Article

\title{
Faculty perception of medical council of India basic course workshop in medical education technologies as faculty development programme
}

\author{
Arvind Kumar Yadav*, Savita Choudhary
}

\begin{abstract}
Department of Pharmacology, Geetanjali Medical College and Hospital, Udaipur, Rajasthan, India
\end{abstract}

Received: 07 March 2016 Accepted: 08 April 2016

*Correspondence to:

Dr. Arvind Kumar Yadav, Email:drakyadav@yahoo.co.in

Copyright: (C) the author(s), publisher and licensee Medip Academy. This is an openaccess article distributed under the terms of the Creative Commons Attribution NonCommercial License, which permits unrestricted noncommercial use, distribution, and reproduction in any medium, provided the original work is properly cited.

\begin{abstract}
Background: There is growing recognition of the importance of basic course workshop (BCW) in medical education technologies (MET) implemented by MCI as faculty development programme. It is now mandatory by the MCI for all the faculty members from Professor to Assistant Professor. So, this study was planned to develop a questionnaire and to use this questionnaire after validation as a tool to assess faculty perception of BCW in MET.

Methods: This is a questionnaire based observational study. After taking the ethical permission from the institutional ethical committee, data was collected in preformed validated questionnaire from all the faculty members who have undergone the basic course workshop at our institute.

Results: Out of total 60 faculty who responded to the questionnaire 50 (83.33) were showing positive response on compulsion of MCI BCW for all faculties and $42(70 \%)$ faculties considered it during post-graduation itself. $56(93.33 \%)$ accepted that this course was beneficial in acquiring new concepts or knowledge. $46(76.66 \%)$ out of total $56(93.33 \%)$ faculty who acquired new knowledge said that they have implemented new acquired knowledge in routine practice and $41(68.33 \%)$ found positive response in students. Only 17 (28.33\%) attended workshop for certificate and promotion consequences in future. 31 $(51.66 \%)$ faculties responded that present modules requires certain changes and $51(85 \%)$ think that implementation of some part of modules require more teaching faculty in department.

Conclusions: BCW must be an integral part of the faculty development programme at institute level but its modules should be regularly updated time to time.
\end{abstract}

Keywords: MCI, BCW, Faculty development programme, Questionnaire, MET

\section{INTRODUCTION}

Faculty development may be defined as an endeavour aimed at promoting faculty success and academic acculturation. Faculty new to the role of academician are often unprepared by degree granting institutions for the unique challenges of an academic career. ${ }^{1}$ So, faculty development is a necessity in any educational system to train faculty for improving their teaching skills. There is growing recognition of the importance of basic course workshop in medical education technologies (MET) implemented by MCI as faculty development programme. It is mandatory now by the MCI for all the faculty members from professor to assistant professor level to undergo the basic course workshop on MET for faculty development. The purpose of the basic course workshop in MET is to provide basic knowledge, skills and attitudes to all faculty members in medical colleges which they can apply in day to day practice in different areas of teaching and assessment (classroom, laboratory, clinical, and field work). The basic course workshop in MET in its present form is operational since six years. The contents of the programme include teaching learning methods, assessment (formative and summative) as well as proposed curricular changes (Integrated teaching, early clinical exposure, internal assessment and E-learning). Minimum duration of the workshop is three days. ${ }^{2}$ Based on experience gained at regional centres and feedback from faculty as well as participants, certain revisions are required to make the course more useful and acceptable to teachers in the current scenario of exploding knowledge. Many times teachers think that; $\mathrm{BCW}$ is 
unnecessary for them as they are already trained and competent enough to teach. So, this study was planned to assess faculty perception of basic course workshop in medical education technologies in our institute which is a tertiary care teaching hospital.

\section{METHODS}

This questionnaire based observational study was conducted in a tertiary care teaching hospital. After taking the ethical permission from the institutional ethical committee; data was collected in preformed questionnaire. Questionnaire was developed and distributed amongst the MEU faculties for validation. Validation of questionnaire was completed after lots of discussion and changes. Questionnaire was distributed to all the faculty members who have undergone $\mathrm{BCW}$ in MET in our institute except the MEU members who were involved in validation of questionnaire. For questionnaire item 1-3 and 5-9, all the participants were requested to respond in a 5 point Likert's scale, where 1 indicates strongly disagree and 5 indicated strongly agree.
But for item no. 4 and 10 they were asked to respond either yes/no or can't say. The questionnaire was anonymous; it had to be voluntarily self-administered. Since it was anonymous, a separate consent form was not collected. In the event that questionnaires were returned filled, consent was implicit; non-consent presumed when questionnaires were returned blank. Data collected in questionnaire was analysed in excel using suitable statistical tests.

\section{RESULTS}

Out of total 70 faculty who had undergone BCW of MET in this institute; 60 faculties participated in this study as all others were members of Medical Education Unit (MEU) who were involved in validation of this questionnaire. There were total 15 Professors, 20 Associate Professors and 25 Assistant Professors of various specialty of the institute with female accounting $40 \%$ and males $60 \%$. Age ranged from 28 to 68 with a mean of 43.83 year. (Table 1), (Figure 1) and (Figure 2) are showing the responses of the faculty.

Table 1: Faculty response of MCI basic course workshop in medical education technologies for all questionnaire items.

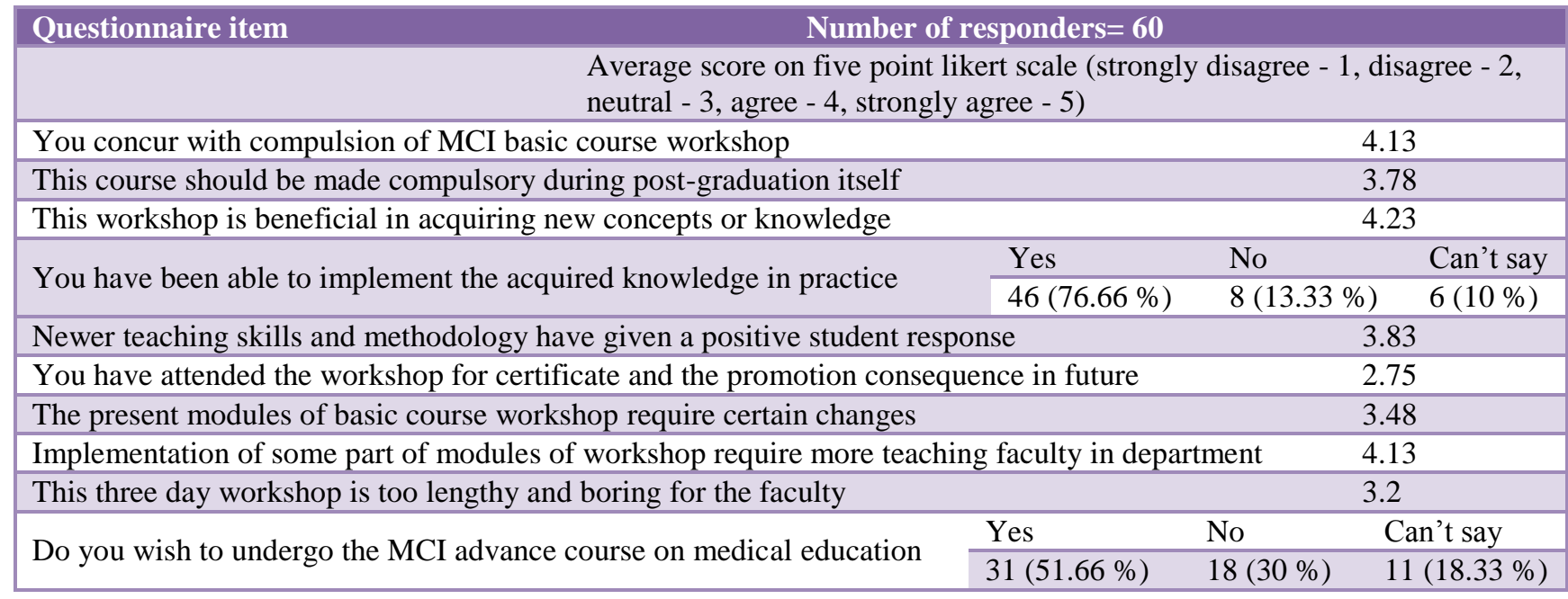

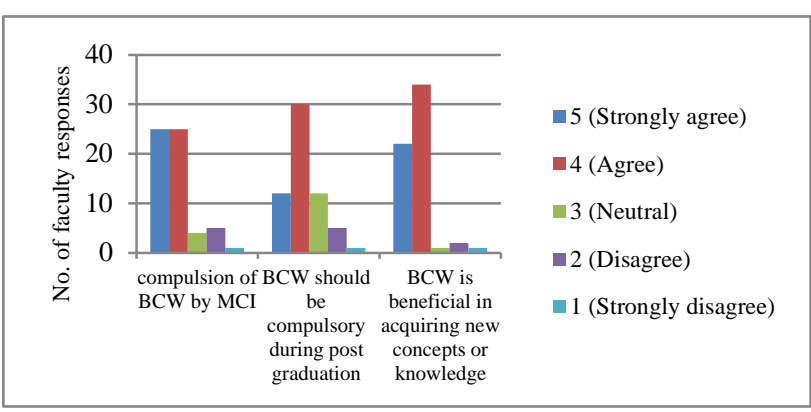

Figure 1: Faculty responses $(n=60)$ on Likert scale for question item 1 to 3 .

\section{DISCUSSION}

Many faculty members in medical education institutions complete their degree programs with a deep knowledge of their disciplines, but generally have little or no educational basics of classroom teaching; these workshops like BCW were developed to address that gap. ${ }^{3}$ This is the first study to report results of perception of faculty for BCW. This study provided an overview of faculty perception and allowed areas of concern to be highlighted. Out of total 60 faculties who responded the questionnaire $83.33 \%$ faculty were showing positive response on compulsion of $\mathrm{MCI} \mathrm{BCW}$. These results 
seem to be in consistent with the compulsion of this course for all the faculty from professor to assistant professor level. $^{2}$ Similar types of results were found for compulsion of this course in postgraduate too. $70 \%$ faculty were showing positive response on compulsion of
MCI BCW during postgraduate. This could be because most of the faculty think that after doing post-graduation they are bound to teach undergraduate students if they join teaching institute. So early exposure is better for them for this type of course.

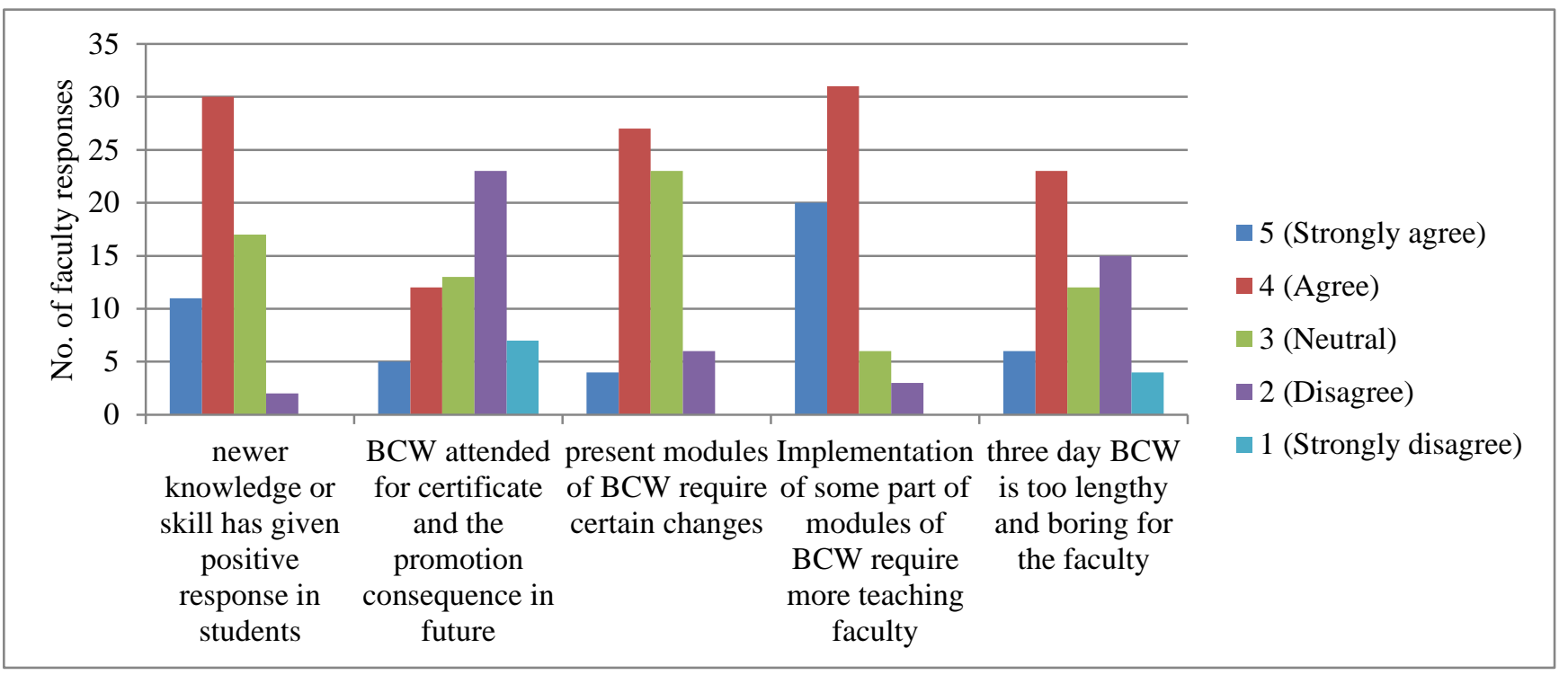

Figure 2: Faculty responses $(n=60)$ on Likert scale for question item 5 to 9.

93.33\% accepted that this course was beneficial in acquiring new concepts or knowledge from basic MET workshop. Similar results were found in other study in which $91.93 \%$ of faculty accepted the usefulness of basic MET. $^{4}$

$76.66 \%$ faculty out of total $93.33 \%$ faculty who acquired new knowledge said that they have implemented new acquired knowledge in routine practice and $68.33 \%$ found positive response in students. This shows that $\mathrm{BCW}$ is very much helpful to them in routine practice. The role of teachers training in improving teaching effectiveness is well established. ${ }^{5,6}$ These activities are highly valued by participants, and definite changes in learning and behaviour are reported by them. ${ }^{7}$

Only $28.33 \%$ faculties attended workshop for certificate and promotion consequences in future. It means that most of the faculty were motivated to attend workshop for knowledge. $51.66 \%$ faculty responded that present module of $\mathrm{BCW}$ require certain changes. $85 \%$ think that implementation of some part of modules of $\mathrm{BCW}$ require more teaching faculty in department. Reason for this could be that in recent time MCI have decreased the faculty in various department and some concepts like objective structured clinical exam/practical exam (OSCE/OSPE) require more faculties in department.

$48.33 \%$ faculty think that three day workshop is too lengthy and boring for the faculty. This could be because clinical side faculty find difficult to attend lengthy workshop on the cost of patient care. This shows that some faculty needs few modifications in time as well as in module of $\mathrm{BCW}$.

\section{CONCLUSION}

Most of the faculty agreed on compulsion of BCW for all the faculty of medical college and they also thought that it should also be made compulsory during post-graduation itself. Majority of faculty thought that BCW was helpful in acquiring new concepts or knowledge. More than fifty percentage of faculty thought that present module of basic course required some changes and implementation of some parts of modules of $\mathrm{BCW}$ require more teaching faculty in the department. So, BCW must be an integral part of the faculty development programme at institute level but its modules should be regularly updated time to time. As this study was questionnaire based and no open ended questions were asked. So, more studies with open ended questions are required.

\section{ACKNOWLEDGEMENTS}

Authors acknowledge the help and support of medical education unit (MEU) members, participants of GMCH, Udaipur and Ahmedabad nodal centre resource faculty of MCI advance course in medical education.

Funding: No funding sources

Conflict of interest: None declared

Ethical approval: The study was approved by the Institutional Ethics Committee 


\section{REFERENCES}

1. Puri A, Graves D, Lowenstein A, Hsu L. New faculty's perception of faculty development initiatives at small teaching institutions. ISRN Education. 2012;2012:9.

2. Faculty development programme. Available at http://www.mciindia.org/InformationDesk/ForColleg es/FacultyDevelopmentProgrammes.aspx.

3. Al-Musawi AS. Faculty perceptions of the professional development workshops conducted at Sultan Qaboos University. Journal of University Teaching and Learning Practice. 2008;5(2).
4. Purandare S, Vagha S. Perception of faculty who have undergone the basic course of medical education technology about the module of basic course workshop by medical council of India. JHSE. 2015;2(1):7-12.

5. Griffith $\mathrm{CH}$. Evidenced-based educational practice: The case for faculty development in teaching. Am J Med. 2000;109:749-52.

6. Steinert Y, Mann K, Centeno A, Dolmans D, Spencer $\mathrm{J}$, Gelula M, et al. A systematic review of faculty development initiatives designed to improve teaching effectiveness in medical education: BEME Guide No. 8. Med Teach. 2006;28:497-526.

7. Jawaharlal Nehru Medical College. Available at http://www.jnmc.edu/collabo.html.

Cite this article as: Yadav AK, Choudhary S. Faculty perception of medical council of India basic course workshop in medical education technologies as faculty development programme. Int J Basic Clin Pharmacol 2016;5:846-9. 